\title{
Hybrid Jute/Glass Reinforced Laminate Mechanical Properties
}

\author{
Hamza Bouguessir*, Elhaddi Harkati and Rokbi Mansour
}

Larbi Tbess Tebessa University, 12002 - Algeria

\begin{abstract}
In the two last decades, extraction and use procedures of natural fibers have known an important increase for the reinforcement of composite materials called 'Bi-composites'. This category of fibers possesses a lot of advantages upon those traditional synthetic such as: Abundantly available, reduced cost, lightness and satisfactory specific performances. The current study has the aim of characterizing a new hybrid laminate made up of 4 plies; the upper and lower ones are reinforced with glass bidirectional fabrics while the two central ones are reinforced with natural Jute woven fabrics.

The main idea of this work is to preserve sufficient mechanical characteristics by reinforcing the most solicited layers with glass fabric and, in the same time, to ensure an economy and a reduced weight through the reinforcement of the intermediary layers by Jute fabrics. The mechanical characterization was carried out by two kinds of static trials: uniaxial tensile test, three points bending and ILSS tests in order to compare the mechanical properties of this composite laminate with those of a four layers totally glass reinforced laminate. The mechanical trials have given us characteristics, values of the hybrid laminate superior than those of the synthetically reinforced laminate in terms of Flexion and ILSS Strengths but lower in terms of tensile strength. And yet, performances obtained with hybrid Jute/ Glass reinforced laminates allow a prediction of actual perspectives for substituting glass fiber by others natural for semi- structural moderately loaded elements applications to combine performance and economy.
\end{abstract}

Keywords: Bio composites; Glass fibers; Mechanical characterization; Natural fibers

\section{Introduction}

The greatest challenge, nowadays, in all science fields is to face the rarefaction of fossil resources. The solution in civil engineering and in transportation is to lighten the construction materials. For this end, the composite materials have been, logically, imposed since the second half of the past century thanks to their specific mechanical characteristics [1]. These materials are emerging quickly as the potential substitute to the metal or ceramic based materials in number of applications including: automotive, aerospace, marine, sporting goods, electronic industries and for retrofitting the corrosion-damaged reinforced concrete elements $[2,3]$. These wonder materials with lightweight, high strength-to-weight ratio and stiffness properties have come a long way in replacing, technically and economically, the conventional materials like metals, wood etc. The replacement of steel with composites can save a 60-80 percentage of component weight and 20-50 weight percentages with the aluminium components [4]. Moreover, their cost has significantly decreased over the past years due to improvement of manufacturing [5]. The properties of polymers are modified using reinforcement fibers for optimizing the mechanical properties. Fiber, yarn and fabric are some of the reinforcement forms that are usually applied to fiber reinforced composites and these forms have been applied since before world-war II. The most used fibers are: Carbon, aramid and glass ones. Fiber glass is a light weight, strong and robust material used due their excellent properties. Although strength characteristics are somewhat lower than carbon fiber and it is less stiff, the material is typically far less brittle and its raw materials are too much cheaper [6]. Non degradability, High cost of synthetic fibers and their health hazards have really necessitated the exploration of natural fibers; consequently, these latter have always formed wide applications from the time they gained commercial recognition [7]. Government regulations and a growing environmental consciousness throughout the world have generated a paradigm to move in the direction of designing materials compatible with the environment [8]. The early part of the 21 century gave more focus on renewable sources of natural fibers, mainly for composite materials applications in response to environmental issues [9] Natural fiber reinforced composites were introduced since 1908 when, for the first time, cellulose fibers were incorporated in phenolic resins [10]. The advantages of natural fibers include: abundant sources in the nature, renewability, biodegradability, nontoxicity, low cost, easy processing, low specific gravity, high toughness, acceptable specific strength, sustainable resource, good thermal properties and enhanced energy recovery [11-14]. Diversification of jute fibers from their traditional markets to other potential sectors (building and furniture) has gained interest in developing countries to meet the pressing demands of conventional materials, especially wood substitutes. [15].

In the last years, Natural fiber reinforced composites are gaining interest in diversified applications: Non-structural parts of automotive industry [16], housing, railways and aerospace applications $[17,18]$. The wide applications of NFPC's are growing rapidly in numerous engineering fields; a great importance in different automotive applications by many automotive companies (BMW, Mercedes, Chrysler, Ford and Opel). Beside the auto industry, the applications of natural fiber composites have also been found in building and construction industry, the application of natural fiber composites have also been found in building and construction industry, sports, aerospace, panels, windows frame, decking and bicycle frame [19]. Jute is the cheapest lignocellulosic long vegetable bast fiber and abundantly available all over the world [20]. One of the most promising applications of jute is in polymer composites that can be molded into a variety of flat and complex shaped components by exploiting their attractive reinforcing potential. The table below illustrates a comparison between the mechanical properties of Jute fibers and those of Glass ones (Table 1).

The importance of interfacial interactions between the polymer matrix and the fillers was widely reported as to improve

*Corresponding author: Hamza Bouguessir, Larbi Tbess Tebessa University, 12002 - Algeria, Tel: $00213551710826 ;$ E-mail: h.bouguessir@univ-tebessa.dzl

Received June 14, 2016; Accepted July 08, 2016; Published July 10, 2016

Citation: Bouguessir H, Harkati E, Mansour R (2016) Hybrid Jute/Glass Reinforced Laminate Mechanical Properties. J Civil Environ Eng 6: 242. doi:10.4172/2165$784 \times .1000242$

Copyright: ( 2016 Bouguessir H, et al. This is an open-access article distributed under the terms of the Creative Commons Attribution License, which permits unrestricted use, distribution, and reproduction in any medium, provided the original author and source are credited. 
the hygrothermal stability and mechanical properties of polymer composites. This is why several techniques have been applied to remove incompatibility problems by using coupling agents and/or chemical surface fillers modification. Another way to improve the properties of composites is to use more than one type of reinforcement and produce hybrid composites. These materials are one of the most promising areas in polymer composites. By using a combination of inorganic and organic fillers (hybridization) in thermoplastics leads to the development of hybrid organic/inorganic polymer composites [21-23]. Many authors have reported the mechanical properties of natural fiber reinforced composites. But less effort has been focused on Natural-glass fiber reinforced polymers. So this paper provides overview of Natural-glass fiber reinforced polymers [24]. The aim of this study is to manufacture, characterize and compare the properties of a Hybrid composite laminate reinforced with raw Jute/Glass fabrics with another Glass fiber reinforced laminate. Our targeted objectives through this research work are:

- Using renewable resources.

- Reduce Health problems and Skin irritations during manufacturing.

\begin{tabular}{|c|c|c|c|c|c|}
\hline $\begin{array}{c}\text { Fiber } \\
\text { Type }\end{array}$ & $\begin{array}{c}\text { Density } \\
\left(\mathbf{g} / \mathbf{c m}^{3} \mathbf{)}\right.\end{array}$ & $\begin{array}{c}\text { Elongation } \\
\text { (\%) }\end{array}$ & $\begin{array}{c}\text { Tensile } \\
\text { Strength (MPa) }\end{array}$ & $\begin{array}{c}\text { Young's Moudulus } \\
\text { (GPa) }\end{array}$ & $\begin{array}{c}\text { Specific } \\
\text { modulus (GPa) }\end{array}$ \\
\hline Jute & 1.3 & $2-3$ & $350-770$ & $12-26$ & $9-20$ \\
\hline $\begin{array}{c}\text { Glass } \\
\text { E }\end{array}$ & 2.5 & 4.4 & $2000-3400$ & $70-73$ & $27-28$ \\
\hline
\end{tabular}

Table 1: Mechanical characteristics of jute and glass fibers $[21,22]$.

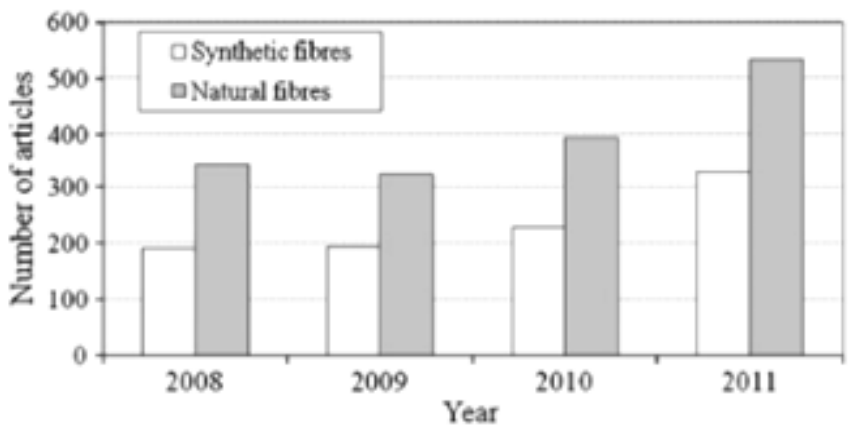

Figure 1: Number of published articles studying composites reinforced with synthetic and natural fibers [18].

\begin{tabular}{|c|c|}
\hline Trial Type & ASTM Standard \\
\hline Tensile test & D3039 \\
\hline Three points bending & D790 \\
\hline ILSS & D2344 \\
\hline
\end{tabular}

Table 2: Trials and their standards.

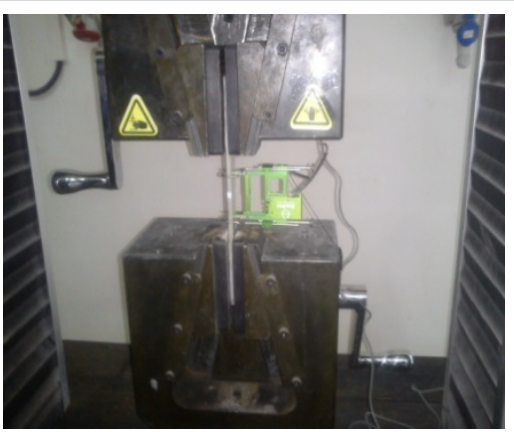

Figure 2 : Tensile test set-up.
- Increase the cost/performance ratio.

- Protecting our environment and its resources.

\section{Materials and Methods}

\section{Materials}

Polymer binder: The thermosetting isophtalic unsaturated polyester UPE resin has a density of $1.2 \mathrm{~g} / \mathrm{cm} 3$, viscosity at $25^{\circ}$ equals $426 \mathrm{mPas}$ and a gel time at $25^{\circ}$ equals $14^{\prime} 30^{\prime \prime}$. The UPE resins are a commercially available polymer binder and are most frequently used thermosetting matrices owing to their low cost an adaptability to be transformed into large composite structures. Catalyst and accelerator in a weight ratio of 1:0.003:0.02.

Jute fibers: Jute is a bast fiber obtained from inner tissues of the plant stem. The fibers are bound together by gummy materials (pectinous substances) which keep the fiber bundles cemented with non-fibrous tissues of Jute bark. These encircling soft tissues must be softened, dissolved and washed away so that the fiber can be obtained from the stem. This is done by steeping the stems in water and it is known as retting. The optimum water temperature for retting is $80^{\circ} \mathrm{F}$. Micro-organisms (mainly bacilous bacteria) decompose the gums and soften the tissues in 5 to 30 days depending upon temperature and the type of water used. It has been found that the presence of higher amounts of calcium and magnesium tend to increase the tenacity of fiber. We have used raw 'as received' jute fabrics without any further treatments. The approximate chemical composition of Jute fiber in wt $\%$ is: cellulose 71.5 , hemicelluloses 13.4 , pectin 0.2 , lignin 13.1 , water soluble compounds 1.2, fat and waxes 0.6. [25] (Figure 1).

Fabrication method : The composite laminates that were made in this study were fabricated by a simple hand lay-up technique. Each plate was constituted of 4 layers of reinforcement fabrics impregnated in pre-catalyzed binder. After manufacture, the composites stayed 24 hours to have a total polymerization [26]. Hybrid Jute/Glass and Glass reinforced laminates were characterized for their mechanical properties upon specimens cut with diamond saw from the above manufactured polymer composite plates according to universal standards as described in the Table 2 below:

Mechanical characterization: Tensile, flexural and ISS test were performed on a computerized Universal Testing machine UTM YLE 25 having a maximum capacity of $250 \mathrm{KN}$. All the tests were done at an ambient temperature.

Tensile strength test: The specimens of dimensions $250 \mathrm{~mm} \times 25$ $\mathrm{mm} \times 8 \mathrm{~mm}$ were used for analysis. The tensile test was conducted in according with ASTM D3039 method (Figure 2). The test was conducted at the constant strain rate of $1.5 \mathrm{~mm} / \mathrm{min}$. Force was applied until the failure of the sample and load-elongation curve was obtained. The tensile modulus and strength were calculated through the formulas:

$$
\begin{aligned}
\mathrm{R}_{\mathrm{T}} & =\mathrm{F}_{\mathrm{U}} / \mathrm{A} \\
\mathrm{E}_{\mathrm{L}} & =\left(\mathrm{F}_{1}-\mathrm{F}_{2}\right) /\left\{\left(\varepsilon_{1}-\varepsilon_{2}\right) \times A\right\} \\
\varepsilon \mathrm{U} & =\mathrm{FU} /(\mathrm{ELx} \mathrm{A})
\end{aligned}
$$

where, FU: ultimate load (N), F1 and $\varepsilon 1$ : The load and the strain at $50 \%$ of FU, F2 and $\varepsilon 2$ : The load and the strain at $20 \%$ of FU. $\varepsilon U$ : the ultimate strain.

Flexural strength test: The Three-point bend flexural test was conducted in accordance with ASTM D790 Figure 3. The speed rate was 2 $\mathrm{mm} / \mathrm{min}$. Flexural strength is determined from the formula given below:

$$
\mathrm{R}_{\mathrm{F}}=3 \mathrm{FL} / 2 \mathrm{bd}^{2}
$$




$$
\mathrm{E}_{\mathrm{F}}=\mathrm{L}^{3} \mathrm{~m} / \mathrm{bd}^{3}
$$

Where: F: Ultimate load (N), L: Span length (mm), b: wide (mm), d: Thickness ( $\mathrm{mm}$ ), $\mathrm{m}$ : The slop of the curve load-bending in the linear zone.

Inter-laminar shear strength test: This test was carried out mainly to determine the delaminating effect of the plies and the inter-laminar shear strength (SH) of the composites according to ASTM D 2344. The specimens had span-to-length ratio of $3 / 7$ and a thickness-to-span ration of $1 / 3$ to avoid the flexural effects. The experimental set-up is illustrated on the Figure 3. (Figure 4)

The Inter-laminar shear Strength $\mathrm{S}_{\mathrm{H}}=0.75 \times \frac{\mathrm{Pd}}{\mathrm{bd}} \mathrm{MPa}$

Where $\mathrm{Pd}=$ breaking load, $\mathrm{N}$.

\section{Results and Discussion}

\section{Tensile strength test}

Generally, the mechanical properties of obtained composites are

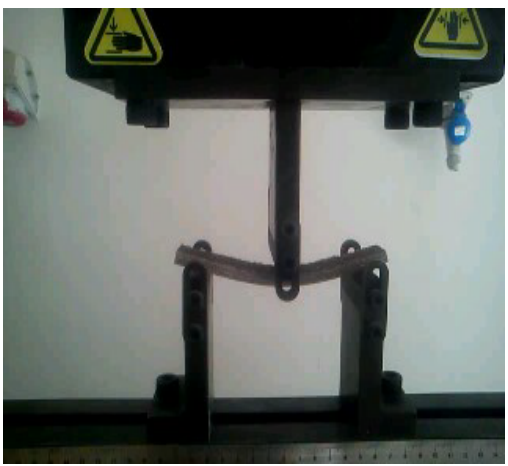

Figure 3: Flexural strength set-up.

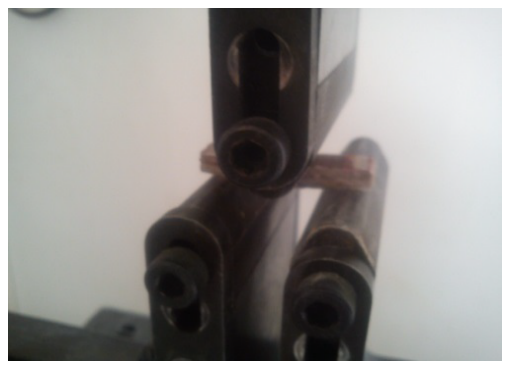

Figure 4: ILSS set-up.

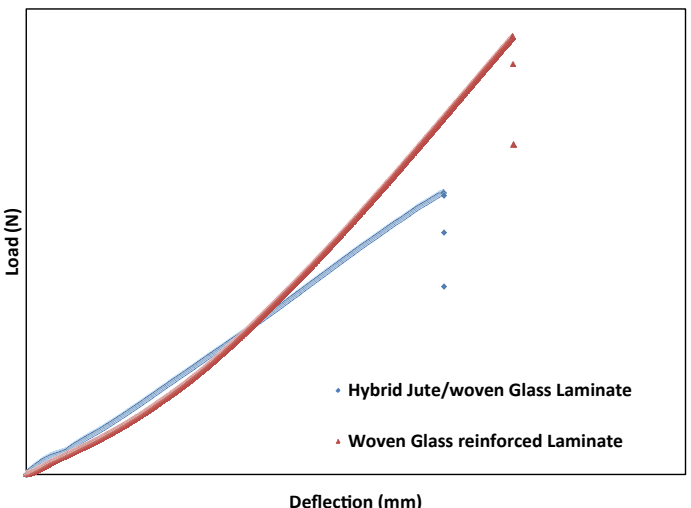

Figure 5: Load-extension of the studied laminates.

\begin{tabular}{|c|c|c|c|}
\hline $\begin{array}{c}\text { Reinforcement } \\
\text { Type }\end{array}$ & Tensile Load (N) & $\begin{array}{c}\text { Tensile Modulus } \\
\text { (GPa) }\end{array}$ & $\begin{array}{c}\text { Elongation at } \\
\text { break (\%) }\end{array}$ \\
\hline Jute Fabric & $8029.5 \pm 1113$ & $5.28 \pm 0.48$ & $7.25 \pm 0.93$ \\
\hline 2D E-Glass Fabric & $14715 \pm 616$ & $27.4 \pm 1.77$ & $8.37 \pm 0.75$ \\
\hline
\end{tabular}

Table 3: Tensile properties of specimens.

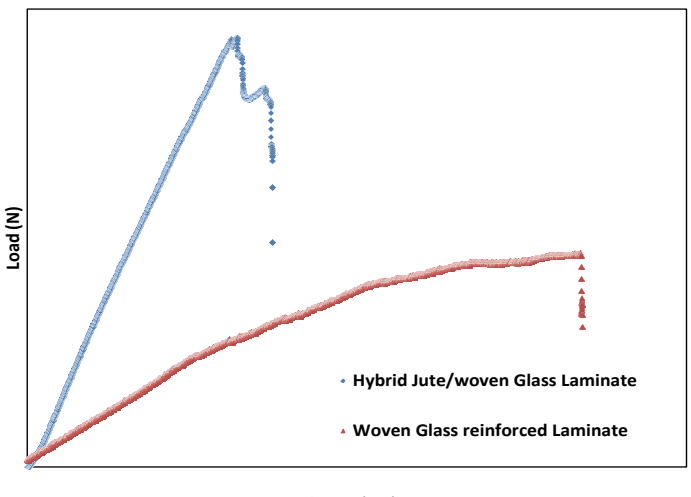

Figure 6: Load-deflection curve of the 3 laminates.

mainly governed by: number of layers, fiber direction, grammage, strength and modulus of the fibers and the effectiveness of the bonding strength between matrix and fibers in transferring stress across the interface [27]. Figure 5 shows the stress-strain diagram for Hybrid jute/ Glass and Woven glass fabric reinforced composites. From the behavior observed, the strain is proportional to the load applied and increases linearly till reaching the maximum load where it exhibits a little nonlinearity before its failure by progressive breaking of the fibers. During the tensile test, the Hybrid Jute/Glass fabric reinforced composites had a width-wise failure perpendicular to the force application axis. In the other hand, the transverse matrix cracking is the first failure mode seen. Hybrid Jute/Glass Fiber reinforced laminates showed catastrophic failure, compared to that of the totally synthesized one, with a violent release of elastic energy that caused explosion of the specimens in their centers. Tensile strength, tensile modulus and elongation at break of the three types of samples are presented in Table 3.

\section{Flexural strength test}

The flexural properties were obtained and are shown on loaddisplacement characteristic curves of the two laminates Figure 6. Samples with span ratio of 16 as suggested by ASTM D790, and five samples were tested for each laminate.

The flexural strength and modulus of Hybrid Jute/Glass fabric reinforced laminate were better than those of the other reinforced with synthetic fabrics. Similar to tensile tests, the failure of Hybrid reinforced laminates took place abruptly while it happened gradually for the synthesized specimens. The final flexural fracture was caused by simultaneous compressive and tensile failure, on the upper and the inferior layers respectively. The flexural characteristics were lower than that of tension. One possible explanation of this fact is that the laminated composites were not fully loaded in flexion as it did under tensile loading [28].

The ratio between flexural and tensile strength of the Hybrid natural/Synthetic composites was 6,8 and 1,8 for synthesized ones and that explains the better flexural behavior of the Hybrid Jute/Glass composites that its tensile one. (Table 4).

\section{Short beam test}

ASTM D2344 specimens were cut with lengths resulting in a span/ 
thickness ration of 3 for the three types of composites laminates. The span was chosen in order to avoid flexural effects that could change the desired shear failure mode. Typical load-deflection curves for five samples subjected to shear strength tests are shown in Figure 7.

As per the flexural and tensile tests, interlaminar shear strength and modulus of Glass fibers reinforced laminates were better than that of natural fibers. This is due to the poor interfacial adhesion because of hydrophilic nature of natural fiber in contrast of the hydrophobic character of polymer binder $[28,29]$. Accordingly, this fact causes the weakness of bonding between fibers and matrix, which is the main controller of the strength to shear. The averaged ILSS test results are shown in Table 5. Another possible provenance of this difference is that the laminates reinforced with synthesized fibers are better perfomant than those totally reinforced with natural faibers as has been proved in our previous work. The averaged ILSS of the Hybrid fabric reinforced laminates was $1226 \pm 100(\mathrm{~N})$.

\section{Conclusion}

The effect of reinforcement fabric nature on the mechanical behavior of two types of composite laminates was examined. Generally, the mechanical properties of obtained synthesized composites are higher than those of Natural fabric reinforced one. According to the results obtained, The Hybrid Jute/glass reinforcement is sufficiently stiff and strong to be introduced in composite laminates with thermosetting matrix. Although the Jute fibers have a rough surface, their bonding strength with polymer matrix is weak requiring prior chemical treatments. The Flexural and Interlaminar Shear properties of the Hybrid laminate were better than those of the synthetic reinforced one even thought tensile properties of this latter were better than those of the Hybrid laminate. The Incorporation of natural fibers with GFRP can improve the properties and used as an alternate material for glass fiber reinforced polymer composites.

The Hybrid natural/Glass fiber reinforced polymer composites can be a promising alternative to their synthesized homologue because

\begin{tabular}{|c|c|c|}
\hline Reinforcement type & Flexural Load (N) & Flexural modulus (GPa) \\
\hline $\begin{array}{c}\text { Hybrid Jute/Glass } \\
\text { laminate }\end{array}$ & $547.8 \pm 47$ & $2.6 \pm 0.28$ \\
\hline 2D E-Glass Fabric & $277.6 \pm 20$ & $11.02 \pm 1.3$ \\
\hline
\end{tabular}

Table 4: Flexural characteristics of the laminates.

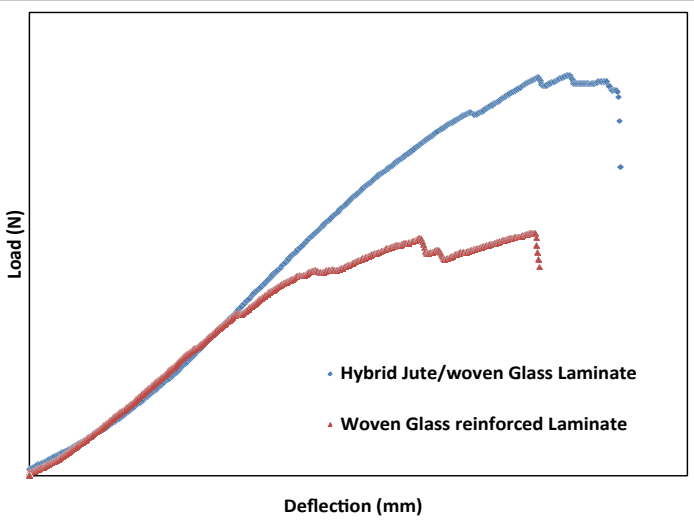

Figure 7: Load-deflection of ILSS test.

\begin{tabular}{|c|c|}
\hline Reinforcement type & Interlaminar Shear Strength (MPa) \\
\hline Jute Fabric & $1226 \pm 100$ \\
\hline 2D E-Glass Fabric & $753 \pm 62$ \\
\hline
\end{tabular}

Table 5: Inter-laminar shear strength properties of the samples. they have beneficial properties such as low density, less expensive, thus, providing advantages for utilization in commercial applications ; automotive industry, buildings and constructions.

\section{References}

1. Jérémie $A$ (2009) Comparative study of the behavior of composite thermosetting or thermoplastic matrix. Doctoral thesis, 1: 219.

2. Vijay KT, Manju KT (2014) Processing and characterization of natural cellulose fibers/thermoset polymer composites. Carbohydrate Polymer 109: 102-117.

3. Jian-He X, Ruo-Lin H (2012) Experimental study on rehabilitation of corrosiondamaged reinforced concrete beams with carbon fiber reinforced polymer. Construct and Build Mater 38: 708-716.

4. Ajith G, Senthil KM, Elayaperumal A (2014) Experimental Investigations on mechanical properties of jute fiber reinforced composites with polyester and epoxy resin matrices. Procedia Eng 97: 2052-2063.

5. Konstantinos G (2013) Inelastic behavior of polymer composites, Doctoral Thesis, Lulea University of Technology, 9: 184.

6. Ramesh M, Palanikumar K, Hemachandra RK (2013) Mechanical property evaluation of sisal-jute-glass fiber reinforced polyester composites. Composites: Part B, 48: 1-9.

7. Christopher CL, Christian EO, Chris IO (2013) Natural fiber composite design and characterization for limit stress prediction in multiaxial stress state. Article in press. J King Saud University-Engineering Sciences.

8. Emanuel MF, Vitor MC, Joao FM, Rui LR (2013) Novel cork-polymer composites reinforced with short natural coconut fibers: Effect of fiber loading and coupling agent addition. Composites Sci Technol 78: 56-62.

9. Umar $\mathrm{N}$, Jamil $\mathrm{H}$, Megat $\mathrm{AMHH}$ (2015) A review on triboligical performance of natural fibre polymeric composites. Tribology Int 83: 77-104.

10. Lazaros T, Subhas D, Sandip R, Dieter F, Edith M et al. (2014) High Performance natural rubber composites with a hierarchical reinforcement structure of carbon nanotube modified natural fibers. Mater and design 58: 1-11.

11. Andrzej KB, Wenyang Z, Andris C (2001) Natural-fibre-renforced polyurethane microfoams. Composites Sci and technol 61: 2405- 2411.

12. Raghad HM, Mustafa AH, Noor SS (2010) The edition effect of natural fibres on polymeric materials and study some of thermal and mechanical properties. $J$ Al-Nahrain University 13: 84-90.

13. Amar SS, Vijay KTH (2008) Fabrication and study of lignocellulosic Hibiscus Sabdariffa fiber reinforced polymer composites, peer-reviewes article. Bio Resources 3: 1173-1186.

14. Pruttipong $P$, Warunee $A$, Tawatchai $M$, Rattiyakom $S$, Ketsara $A$, et al. (2014) Effect of modified jute fiber on mechanical properties of green rubber composite. Energy Procedia 56: 641-647.

15. Singh B, Gupta M, Anchal V (2000) The durability of jute fibre-reinforced phenolic composites. Composites Sci and Technol 60: 581-589.

16. Giuseppe C, Alberta L, Giuseppe R, Gianluca C (2010) Composites based on natural fibre fabrics, Woven fabric Engineering. Polona Dobnik Dubrovski (ed), ISBN: 978-953-307-194-7, Intech.

17. Sukhdeep S, Dharmpal D, Lakshya A, Gupta VK (2014) Tensile and flexural behavior of hemp fiber reinforced virgin-recycled HDPE matrix composites. Procedia Mater Sci 6: 1696-1702.

18. La SDE, Et T (2013) Analysis of the feasibility of eco-design of composite parts based on renewable resources for medical purposes.

19. Layth M. Ansari MNM, Grace P, Mohamed J, Islam MS (2015) A review on natural fiber reinforced polymer composite and its applications, Hindawi publishing corporation. Int J Polymer Sci 15.

20. Rezaur Md R, Monimul Md H, Nazul Md MH (2008) Improvement of physicmechanical properties of jute fiber reinforced polypropylene composites by post-treatment. Composites: Part A, 39: 1739-1747.

21. Gianluca C, Giuseppe C, Giuseppe R, Alberta L (2010) Composites based on natural fibre fabric. Woven Eng 978-953-307-194-197.

22. Andrzej KB, Wenyang Z, Andris C (2001) Natural-fibre-renforced polyurethane microfoams. Composites Sci technol 61: 2405-2411. 
Citation: Bouguessir H, Harkati E, Mansour R (2016) Hybrid Jute/Glass Reinforced Laminate Mechanical Properties. J Civil Environ Eng 6: 242. doi:10.4172/2165-784X.1000242

23. Essabir H, Boujmal R, Ouadi M, Rodrigue D, Bouhfid R (2016) Mechanics of materials mechanical and thermal properties of hybrid composites : Oil-palm fiber/clay reinforced high density polyethylene 98: 36-43.

24. Sanjay MR, Arpitha GR, Yogesha B (2015) Study on mechanical properties of natural - glass fibre reinforced polymer hybrid composites : A review. Materials Today: Proceedings 2: 2959-2967.

25. Gowda TM, Naidu ACB, Rajput C (1999) Some mechanical properties of untreated jute fabric-reinforced polyester composites. J Composites: Part A 30: 277-284.

26. Mustapha B, Abderrezak B, Katarzyna B, Fabrizio S, Stuart B (2013) Cactus fibre/polyester biocomposites: Manufacturing, quasi-static mechanical an fatigue characterization. Composites Sci technol 74: 150-159.

27. Hind A, Hala B, Jamal E, Rachid B, Abouelkacem Q (2015) Fabrication, Charcaterization and modeling of laminated composites based on woven jute fibers reinforced epoxy resin. Mater and Design 68: 104-113.

28. Pruttipong $P$, Warunee A, Tawatchai M, Rattiyakom S, Ketsara A, et al. (2014) Effect of modified jute fiber on mechanical properties of green rubber composite. Energy Procedia 56: 641-647.

29. Moyeenuddin AS, Kim LP, Alan F (2012) Flexural properties of hemp fibre reinforced polylactide and unsaturated polyester composites. Composites: Part A 43: 519-526. 